\title{
STRATEGIC PRIORITIES OF THE RELIGIOUS INSTITUTION USING COMBINATION OF SWOT AND FUZZY-AHP. CASE STUDY OF THE CONGREGATION OF MISSIONARIES OF THE SACRED HEART
}

\begin{abstract}
Strategic priorities are quite commonly implemented by both profit and non-profit institutions but quite rarely employed by religious congregations. The congregation of the Missionaries of the Sacred Heart (MSC), an institution in Catholic Church, has undertaken an empirical study, using a combination of SWOT and fuzzy-Analitic Hierarchy Process (AHP) methodologies.
\end{abstract}

Keywords: Swot-fuzzy AHP, religious, MSC, Strategic planning, Catholic, Decision making.

\section{Introduction}

Strategic priorities are commonly applied in modern organisation. The Congregation of Missionary of Sacred Heart (MSC), a Catholic religious organization, is required to set up his strategic priorities to sustain. It is considered as urgent because the Catholic church is facing a huge problem such as the decreasing of vacation of priesthood, sexual abused committed by priests that cost the lost of trust of people to the church. There are still very few studies related to strategic priorities on religious organization particularly religious congregation such as MSC. The study will contribute to the MSC and Catholic religious organization as a whole to implement their programs by setting up first the strategic priorities.

\section{Literature Review}

Every organization both profit and non-profit required strategic planning (Ohoitimur et al, 2019). Strategic planning will strengthen the the organization to manage their internal and external problems. Part of the strategic planning is determining the strategic priorities. The MSC, as a Catholic religious entity, need to determine their strategic priorities which will be appeared in their future programs. The problems being faced by the Church today is very tough such as clerical sex abuse to the childern (Warner, 2019), priest are considere dangerous (Donnelly, 2015), proglem of relationship between the priests and their leaders (McDevitt, 2010), drive the MSC to think about their strategic priorities of their pastoral services and education of their novitiates.

\section{Hypotheses/Objectives}

In this study we aim to establish the most appropriate strategic priorities for the MSC congregation in its service of ministry for the new millennium. We plan to do this by developing an effective Analytic Hierarchical Process (AHP), combining fuzzy-AHP and 
SWOT to develop an integrated process, with a clearer and a more effective set of priorities for ministry today.

\section{Research Design/Methodology}

The researchers together with the MSC leaders used SWOT to analyse the internal and external factors of the Congregation. Alternatives strategis were determined. The next step was the application of AHP and Fuzzy-AHP to find out the strategic priorities. The hierarchy was designed. The first level was determining the goal, the second level was the criteria and the third level was the sub criteria. The criteria and sub criteria were selected by the MSC leaders. The questionnaire, in form of pair-wise comparison matrix, was distributed to the MSC leaders as repondents. Consistency of the data was calculated using the formula of Consistency index and then consistency ratio. If the ratio consistency value $(C R) \leq 0,1(10 \%)$ this means that the respondent's perception is considered consistent and the results of other calculations are considered valid.

\section{Data/Model Analysis}

The criteria, sub-criteria and the strategic alternatives of the SWOT put into hierarchical structure as shown in figure 1 below.

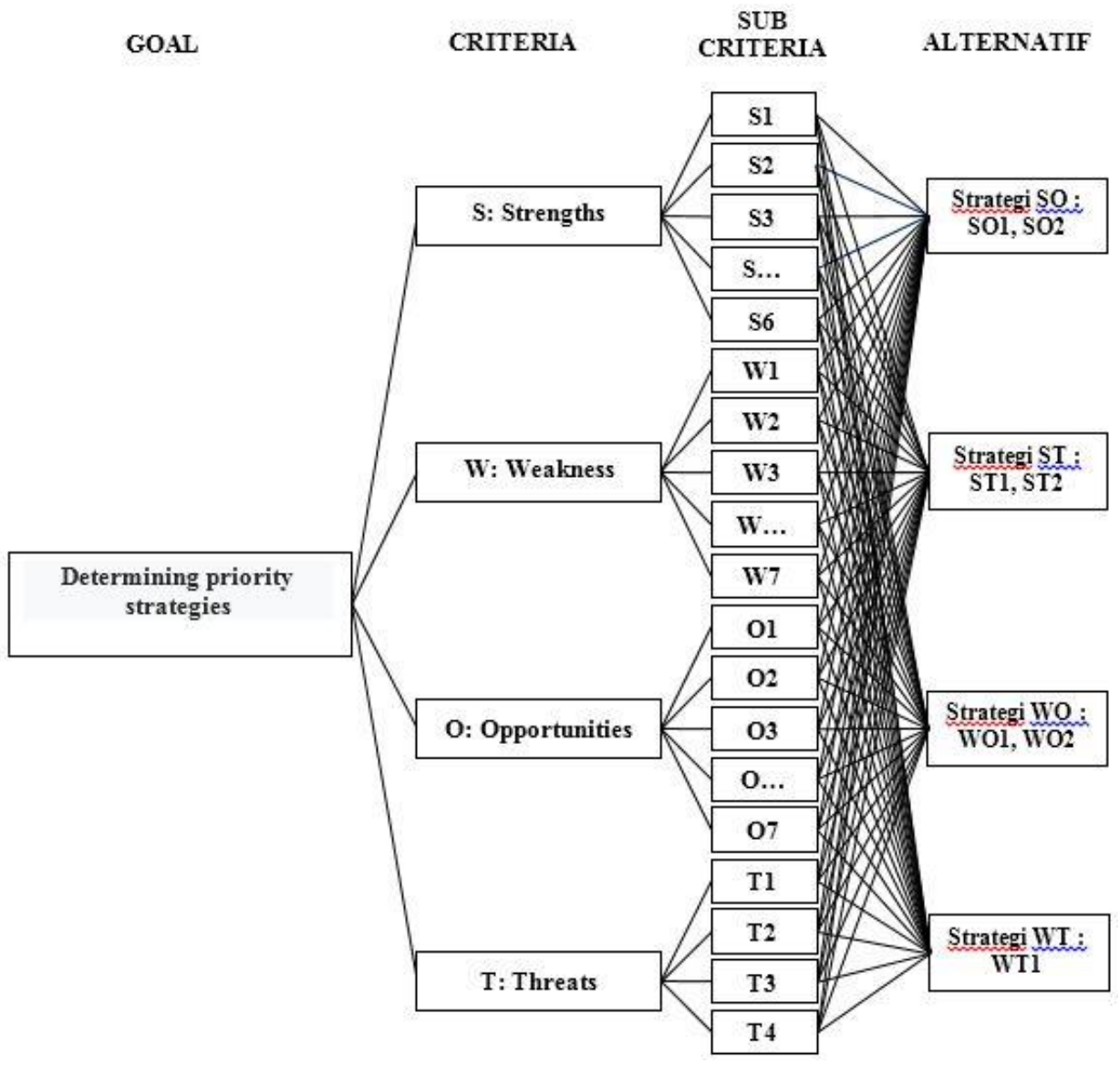

Figure 1. Hierarchy structure of the MSC development

International Symposium on the Analytic Hierarchy Process
DEC. 3 - DEC. 6, 2020 
ISAHP Article: A Style Guide for Paper Proposals To Be Submitted to the International Symposium on the Analytic Hierarchy Process 2020, Web Conference.

The fuzzy pair-wise comparison matrix of the level of importance for the criteria is shown in table 1 below.

Table 1

The fuzzy pair-wise comparison matrix of the level of importance for the criteria

\begin{tabular}{ccccc}
\hline Criteria & $\mathbf{S}$ & $\mathbf{W}$ & $\mathbf{O}$ & $\mathbf{T}$ \\
$\mathbf{( l , ~} \mathbf{m}, \mathbf{u})$ & $(\mathbf{l}, \mathbf{m}, \mathbf{u})$ & $(\mathbf{l}, \mathbf{m}, \mathbf{u})$ & $(\mathbf{l}, \mathbf{m}, \mathbf{u})$ \\
\hline $\mathbf{S}$ & $(1,1,1)$ & $(2.45,3.02,3.59)$ & $(1.41,1.73,2.06)$ & $(2.42,2.94,3.48)$ \\
$\mathbf{W}$ & $(0.60,0.69,0.80)$ & $(1,1,1)$ & $(0.59,0.70,0.89)$ & $(1.30,1.51,1.75)$ \\
$\mathbf{O}$ & $(0.89,1.05,1.25)$ & $(1.83,2.46,3.09)$ & $(1,1,1)$ & $(2.38,3.06,3.75)$ \\
$\mathbf{T}$ & $(0.84,1.05,1.29)$ & $(0.98,1.18,1.41)$ & $(0.46,0.51,0.61)$ & $(1,1,1)$ \\
\hline
\end{tabular}

So the perception weight of the respondent related to the criteria of SWOT $W_{\text {SWOT_Factors }}=(0.555,0,0.445,0)^{T}$. In graphical form displaying below in figure 2 .

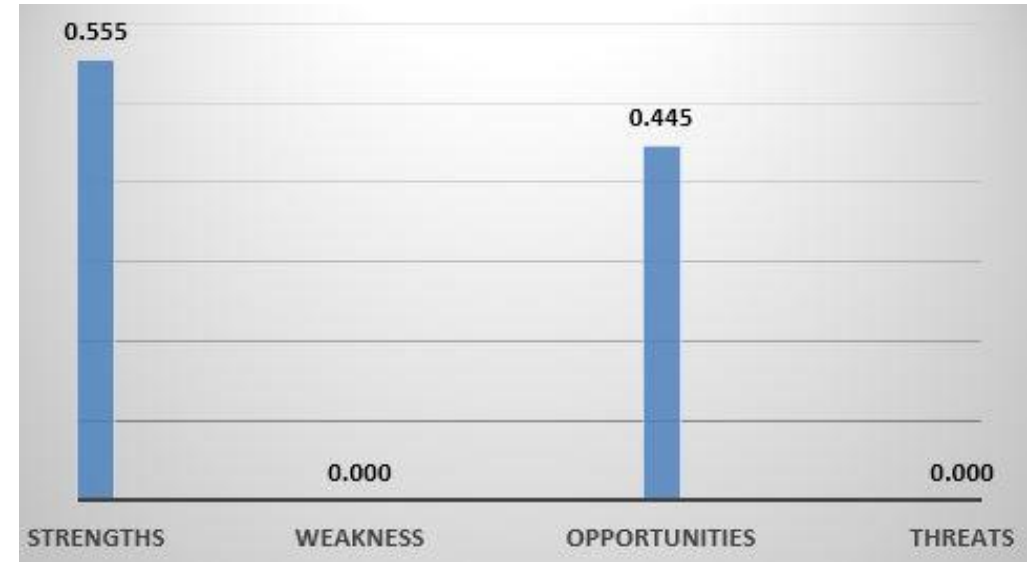

Figure 2. Perception weight of SWOT factors

The priority weight of sub-criteria of SWOT is appeared on figure 3 below

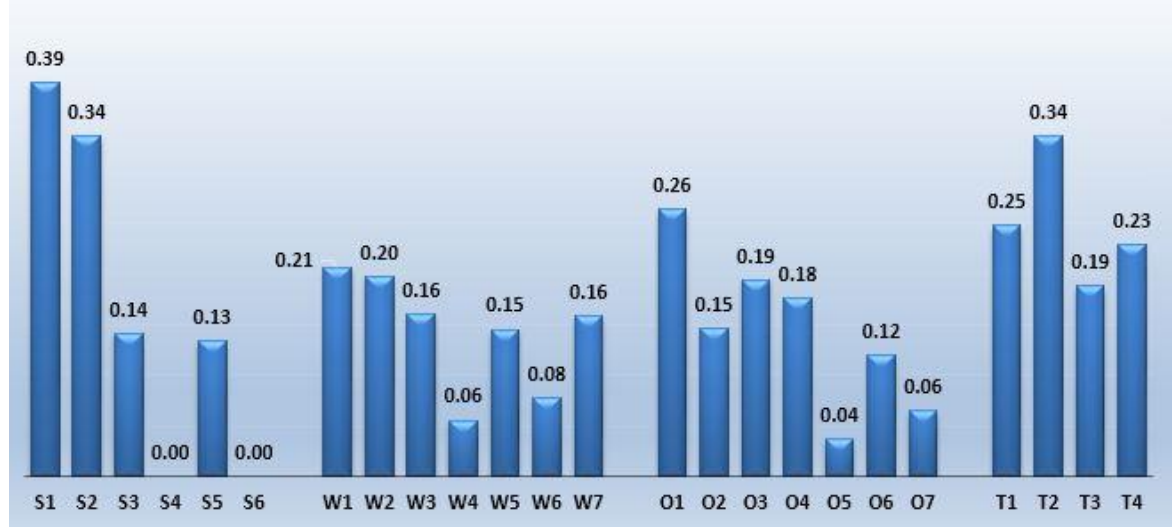

Figure 3. Priority weight of sub-criteria of SWOT 
The final result of the alternative strategy weights are as follows: Strategi $\mathrm{SO}=0.400$, Strategi $\mathrm{ST}=0,291$, Strategi $\mathrm{WO}=0,116$ and Strategi $\mathrm{WT}=0,194$. In graphical form it appears on figure 4 .

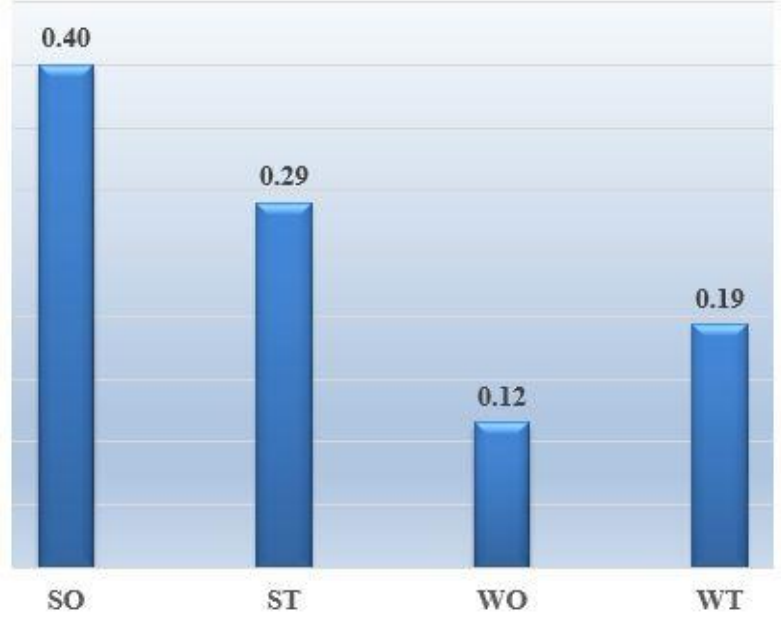

Figure 4. The weights of the alternative strategies

\section{Limitations}

Most of the respondents were not familiar with the AHP and Fuzzy-AHP so the researcher had to explain them before filling up the questionnaire. Limited number of respondents. Very few academic journals and references available

\section{Conclusions}

Determining the strategic priorities is essential for organization. The MSC, as a Catholic congregation, required strategic priorities. The problems facing the church are huge and good strategy will help them to face the difficulties.

\section{Key References}

Donnelly, S. (2016). Sins of the father: unravelling moral authority in the Irish Catholic Church. Irish Journal of Sociology, 24(3), 315-339.

Mcdevitt, P. J. (2010). Ministerial Burnout: Motivation and Renewal for Mission. Pastoral Care and Counceling, 64(4), 1-10.

Ohoitimur, J., Krejci, J., Raco, J. R., Raton, Y., \& Taroreh, F. (2019). ANALYSIS OF THE PASTORAL STRATEGIC PLANNING PRIORITIES OF THE VICARIATE EPISCOPAL OF TONSEA OF THE DIOCESE OF MANADO. International Journal of the Analytic Hierarchy Process, 11(3), 415-434.

Warner, C. M. (2019). The Politics of Sex Abuse in Sacred Hierarchies: A Comparative Study of the Catholic Church and the Military in the United States. Religions, 10(4), 281 